\title{
ARTHROPLASTY WITH A SOLID BONE GRAFT FOR PROTRUSIO ACETABULI
}

\author{
A. W. B. HEYWOOD
}

From Princess Alice Orthopaedic Hospital, Cape Town

\begin{abstract}
A high percentage of hips in patients with rheumatoid arthritis presenting for total joint replacement have protrusio deformity with extremely thin medial acetabular walls. Biomechanical principles suggest that, to prevent inward migration of the acetabular component, the prosthesis should be positioned laterally near the acetabular rim. To reinforce the medial wall, the femoral head is fashioned into a solid graft which is anchored against the medial wall as a plug, minimising the amount of cement used and making the use of wire mesh and restraining rings about the acetabulum unnecessary. A series of nine operations on seven patients is presented. Serial radiographs, tomograms and scintigrams taken after operation suggest satisfactory incorporation of the grafts, and no complications have been encountered in a follow-up period ranging from three months to two years.
\end{abstract}

Protrusio acetabuli occurs frequently in hips affected by rheumatoid arthritis due to the usual pattern of concentric inflammation and the osteoporosis which softens the medial wall of the acetabulum. In a series of 307 hips in patients with rheumatoid arthritis or anklylosing spondylitis, Welch and Charnley (1970) found an incidence of 49 per cent with concentric involvement and 21.8 per cent with protrusio acetabuli. In osteoarthritis the incidence of protrusio is far lower.

This paper will describe a method of grafting the acetabular floor with a solid piece of femoral head at the time of total hip replacement, with the object of positioning the prosthesis laterally and reinforcing the acetabular floor. The results of nine operations followed up for periods ranging from three months to two years will be presented.

\section{BIOMECHANICAL PRINCIPLES}

Figure 1 depicts the calculations of Fischer (1899) which were quoted by Pauwels in 1965 . The resultant force $R$ acting on the femoral head can be resolved into the medially directed force $Q$ which drives the head into the softened ace tabular floor, and the vertical force $L$ which causes the migration to be slightly upwards, resulting in an upward tilting of the acetabular roof. Figure 2 shows how this upward inclination of the acetabulum increases the force $Q$ which now meets diminishing resistance from the progressively weakened medial wall, Once the migration starts, its progress is rapid. Stability is reached only when the greater trochanter abuts on the acetabular rim.

Arai (1975) noted that the resultant force acting on the acetabulum was reduced by the medial position of the femoral head in protrusio acetabuli. The pull of the abductor muscle is correspondingly reduced in protrusio, but after operation the more lateral position of the femoral head results in a more normal abduction force; avulsion of the greater trochanter occurred in 20 hips (four per cent) reported by Arai. The amount by which the central dislocation must be reduced when positioning the prosthetic acetabulum raises a conflict of principles. On the one hand, it is desirable to retain a depth which is sufficient to minimise the forces acting on the hip. On the other hand, central placement of the acetabular component directs the stress lines medially, away from the solid buttress of the ilium, thus favouring central dislocation of the prosthesis. Medial migration of the prosthesis is not uncommon. We have had three such

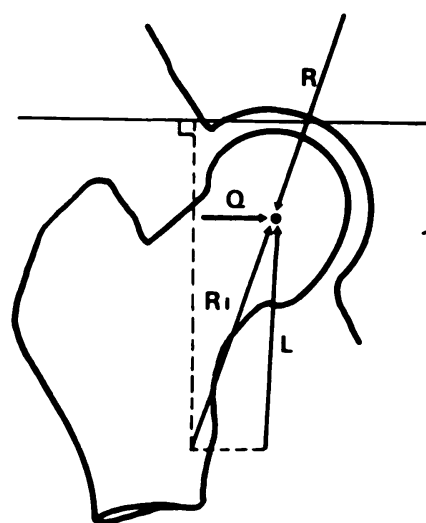

Fig. 1

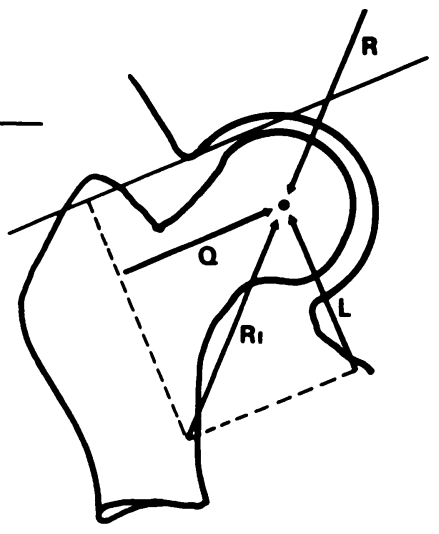

Fig. 2
Figure 1-Resolution of the normal resultant force $R$ into a vertical force $L$ and a smaller horizontal force $Q$ in the normal hip with a horizontal acetabular roof. Figure 2-In protrusio the upward inclination of the acetabular roof increases the now obliquely directed force $Q$ 
Table I. Summary of patients and results

\begin{tabular}{|c|c|c|c|c|c|c|c|c|c|c|}
\hline $\begin{array}{c}\text { Case } \\
\text { number }\end{array}$ & $\begin{array}{c}\text { Age at } \\
\text { operation }\end{array}$ & Side & Sex & Disease & $\begin{array}{c}\text { Duration } \\
\text { of disease } \\
\text { (years) }\end{array}$ & $\begin{array}{l}\text { Duration of } \\
\text { pain in hip } \\
\text { (years months) }\end{array}$ & $\begin{array}{c}\text { On } \\
\text { steroids }\end{array}$ & $\begin{array}{c}\text { Follow-up } \\
\text { (months) }\end{array}$ & $\begin{array}{c}\text { Protrusio } \\
\text { grade }\end{array}$ & Fate of graft \\
\hline 1 & $\begin{array}{l}60 \\
60\end{array}$ & $\begin{array}{l}\mathrm{L} \\
\mathrm{R}\end{array}$ & $\begin{array}{l}M \\
M\end{array}$ & $\begin{array}{l}\text { RA } \\
\text { RA }\end{array}$ & $\begin{array}{l}15 \\
15\end{array}$ & $\begin{array}{l}1 \\
2\end{array}$ & $\begin{array}{l}\text { Yes } \\
\text { Yes }\end{array}$ & $\begin{array}{l}24 \\
24\end{array}$ & $\begin{array}{l}\text { Mild } \\
\text { Severe }\end{array}$ & $\begin{array}{l}\text { Union } \\
\text { Union }\end{array}$ \\
\hline 2 & 71 & $\mathbf{R}$ & $\mathrm{F}$ & RA & 10 & 10 & Yes & 18 & Moderate & Union \\
\hline 3 & 44 & L & $F$ & RA & 20 & 1 & No & 3 & Moderate & Union \\
\hline 4 & 37 & L & $\mathbf{F}$ & RA & 7 & 3 & No & 24 & Mild & Union \\
\hline 5 & $\begin{array}{l}68 \\
68\end{array}$ & $\begin{array}{l}\mathbf{R} \\
\mathbf{L}\end{array}$ & $\begin{array}{l}F \\
F\end{array}$ & $\begin{array}{l}\text { RA } \\
\text { RA }\end{array}$ & $\begin{array}{l}3 \\
3\end{array}$ & 10 & $\begin{array}{l}\text { No } \\
\text { No }\end{array}$ & $\begin{array}{l}5 \\
6\end{array}$ & $\begin{array}{l}\text { Severe } \\
\text { Severe }\end{array}$ & $\begin{array}{l}\text { Union } \\
\text { Union }\end{array}$ \\
\hline 6 & 57 & L & $\mathbf{M}$ & RA & 18 & 4 & No & 12 & Severe & Union \\
\hline 7 & 69 & L & $\mathrm{F}$ & $\mathrm{OA}$ & 6 & 6 & No & 3 & Moderate & Union \\
\hline
\end{tabular}

$R A$, rheumatoid arthritis

OA, osteoarthritis

cases (Figs 3 to 5), Salvati, Bullough and Wilson (1975) reported five, and Charnley (1979) a further five.

In our unit the current policy is to aim at maximal mechanical stability by placing the acetabular component more laterally, near the normal position at the outer lip of the acetabulum; by strengthening the medial acetabular wall with a graft of solid bone; and by minimising the torque strains on the cement-bone interface by using the Charnley low-friction prosthesis with its small head. This paper will be concerned with the technique for strengthening the medial acetabular wall. Hastings recommended grafting a solid femoral head in an acetabular floor that was reinforced with wire mesh and cement (Parker and Hastings 1974; Hastings, personal communication). The technique to be presented is derived from that of Hastings but omits the wire mesh and occasionally involves the use of two small screws for fixation of the graft. The principle is to reinforce the medial wall of the acetabulum with a graft made from the femoral head and to insert this into the acetabulum in such a way that it has maximal contact with the remaining bony bed.

\section{MATERIAL AND METHODS}

Seven patients had operations on nine hips (Table I): one had osteoarthritis and the rest had rheumatoid arthritis. The six rheumatoid patients were remarkable for the short duration, on average 14 months, of symptoms in the hip before they presented with gross abnormality. All were sero-positive and had had rheumatoid arthritis for an average of 11 years. The patient with osteoarthritis had had symptoms of protrusio for six years.

Operative technique. In rheumatoid arthritis the concentric destruction of the femoral head and the acetabulum usually enables the head to be dislocated intact. However, in some patients with rheumatoid arthritis and in most with osteoarthritis and ankylosing spondylitis, dislocation is difficult and the risk of fracture may have to be averted by transecting the neck and removing the head with a "corkscrew". In a minority of patients with very stiff hips the fibrous ankylosis of the head should be accepted and the technique to be described should be abandoned; instead, the medial portion of the head is left in situ and reamed to accept the cup, and the crevice between the remaining head and acetabulum is cleared of fibrous tissue and cortical bone and packed with bone chips to prevent ingress of cement and to promote union between the head and the depths of the acetabulum.

When the head can be dislocated, its medial half is cut off as a hemisphere to become the graft. A misshapen head may also be used, cut off obliquely. If necessary a block of iliac bone could be used instead. In the Charnley arthroplasty, the usual pilot hole is carefully made in the acetabular floor, 20 degrees above the horizontal. The

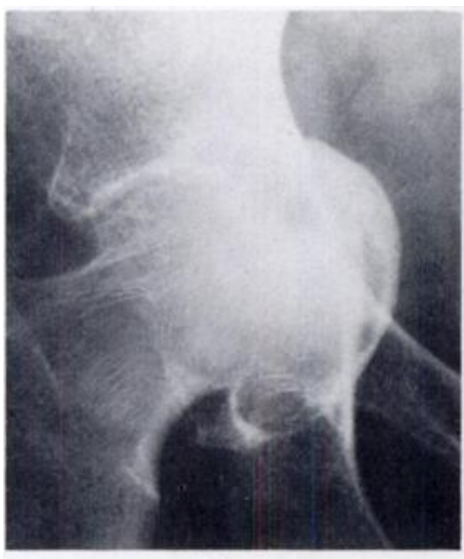

Fig. 3

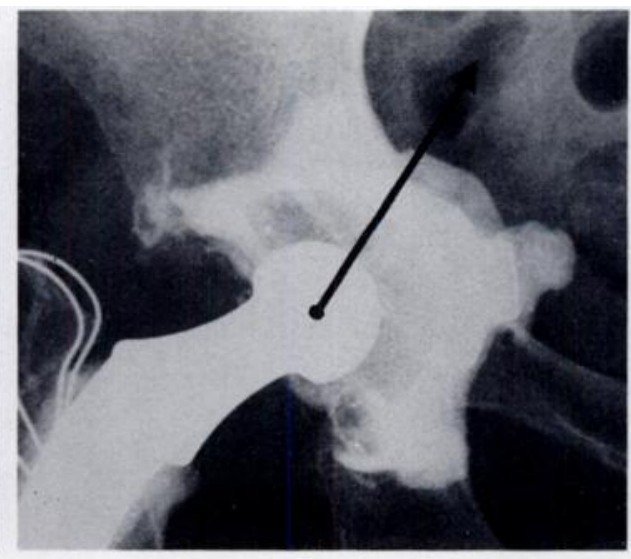

Fig. 4

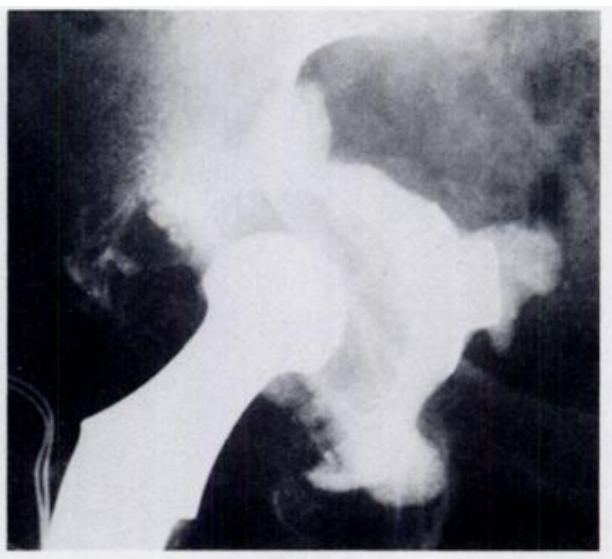

Fig. 5

Figure 3-Protrusio acetabuli due to "idiopathic" osteoarthritis. Figure 4-The same hip after arthroplasty into a medial position. The arrow shows the direction of the resultant stress line. Figure 5-Five years later there has been a central prolapse. 
deepening reamer is used very lightly to scarify the medial wall and the expanding reamer to widen the acetabulum fully. No seating holes for the cement are drilled at this stage.

The hemisphere of bone is next fashioned into a graft as shown in Figure 6. First, cartilaginous remnants, cortex, pannus and erosions are removed down to cancellous bone over the whole articular surface except (in the case of the Charnley arthroplasty) for a nipple-like protrusion, the same width as the acetabular pilot hole and usually two to three millimetres high. on its apex. The cut surface of the hemispherical graft is next scooped out to a concavity with a high-speed burr, leaving bone which varies in thickness from 4 to 10 millimetres, depending on the depth of the defect to be made good.
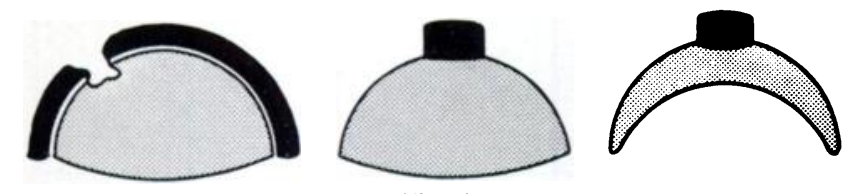

Fig. 6

Cross-sectional diagrams of the steps in shaping the hemisphere of the femoral head into a concavoconvex graft (see text).

The graft is now inserted into the depth of the acetabulum, its "nipple" engaging in the pilot hole. It is hammered firmly into place using the butt end of the Charnley acetabular pusher which moulds it, forcing it against the sides of the acetabulum to obtain a firm fit. The prosthesis is tried to make sure that the graft is not too thick. If it is, more bone is excavated from the concave surface. The prosthesis should be inserted slightly more deeply than normal. If the graft tends to wobble, it may be secured by two 12 -millimetre $\mathrm{AO}$ spongiosa screws inserted close to the edge of the graft and directed radially, away from the medial wall (see Fig. 11). Anchor holes for the cement are now drilled into the acetabular wall and not the graft. Any gaps between the graft and the acetabular bed must be filled with fine bone chips to prevent ingress of cement. The arthroplasty now proceeds in the usual way. In three of our series the contracted superior capsule had to be released, leaving the abductor muscles intact, before the greater trochanter could be comfortably reinserted in its original bed.

The earlier patients were kept on crutches until eight weeks after operation, but in our later patients this precaution was discarded.

\section{RESULTS}

The follow-up ranged from 3 to 24 months, with an average of 15 months. The clinical results in these patients did not differ in any way from those of other patients with rheumatoid arthritis but without protrusio.
In no hip was there sepsis, loosening or structural failure. After operation an assessment was made to determine whether bony union had occurred between the autograft and the depths of the acetabulum.

Radiography showed that, in all cases, bony union had occurred (Figs 7 to 18). Technetium bone-scans on three hips all showed increased uptake in the area of the graft within weeks of the operation (Fig. 13); this was thought to represent the early post-traumatic inflammatory reaction around the graft. Subsequent scans (Fig. 14) done a minimum of six months after operation showed abnormally high uptake in the graft and in the great trochanter, indicating persistent osteogenic activity. Standard tomography was done on the same three hips. The graft appeared separate from its bed soon after the operation, but later tomograms demonstrated consolidation (Figs 17 and 18).

\section{DISCUSSION}

If one regards the mass of the cement and prosthesis as a piston capable of being driven into the acetabular cylinder, then three possible preventive measures emerge. First, the "piston" can be retained by adding a metal-reinforced collar about the acetabular rim; the earlier arthroplasties incorporated cement outside the acetabular rim but many suffered late mechanical failure as adequate bonding can only be obtained inside the bone. Secondly, fixation can be achieved through drill holes into the acetabular walls, which are indeed mandatory. Thirdly, to avoid a bolus of cement in the depths of the acetabulum, a solid graft may be used.

A bone graft has several advantages. A solid bony medial wall offers the most secure bulwark against ingress of the mass of the cement and prosthesis whereas a large bolus of cement causes greater heat as it sets, with the potential for causing necrosis of the surrounding tissue (Jefferiss, Lee and Ling 1975). The conditions favourable to the incorporation of a graft "are most perfectly attained when the cancellous graft is in the form of a solid block rather than when it is in the form of chips, shaves or ribbons". These words, written by Nicoll

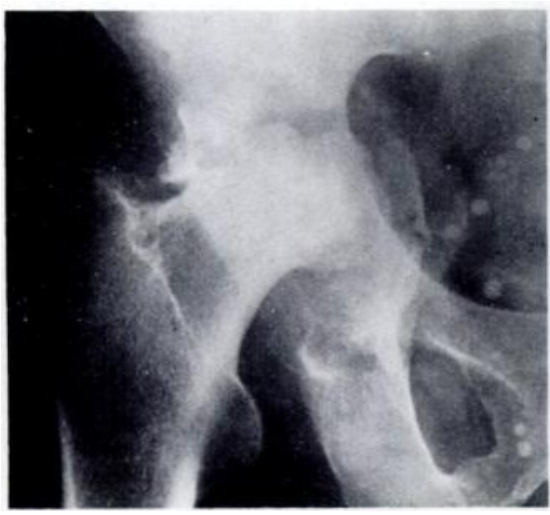

Fig. 7

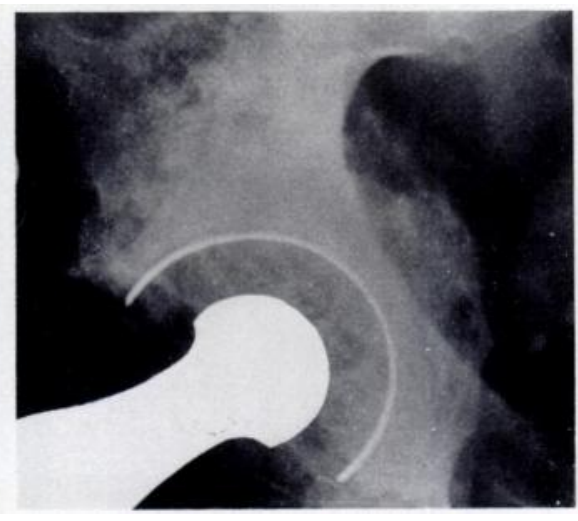

Fig. 8

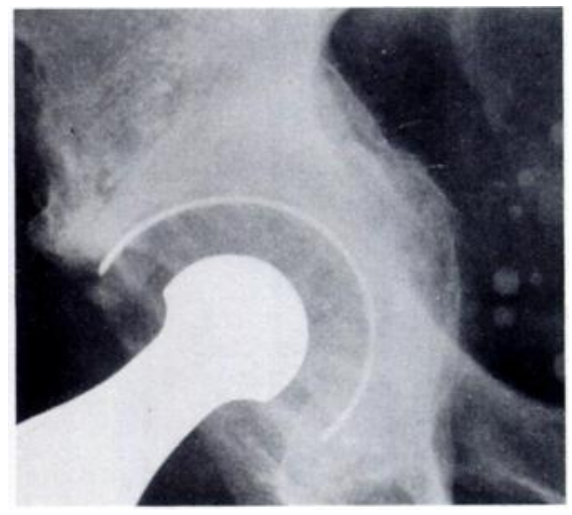

Fig. 9

Figure 7-Protrusio acetabuli due to rheumatoid arthritis. Figure 8-Two weeks after arthroplasty with grafting. Figure 9-Twenty months after operation, the graft appears to have been incorporated. 


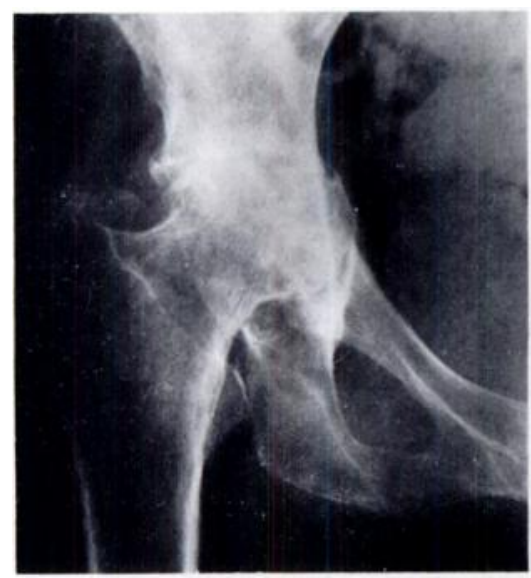

Fig. 10

Figure 10-Protrusio acetabuli due to rheumatoid arthritis. Figure 11-Two weeks after arthroplasty with grafting. The screws gave totally secure fixation, but are unnecessarily long. Figure 12-At five months, incorporation appears complete. Figure 13-Bone scan one month after operation. Figure 14-The same hip six months after operation. Scans done on two other hips showed similar results.

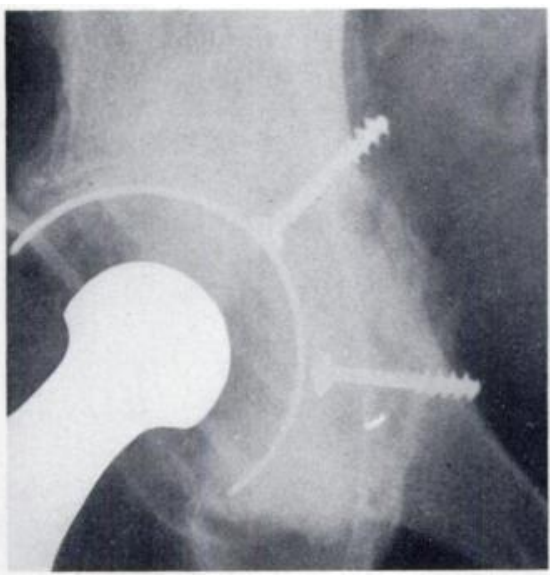

Fig. 11

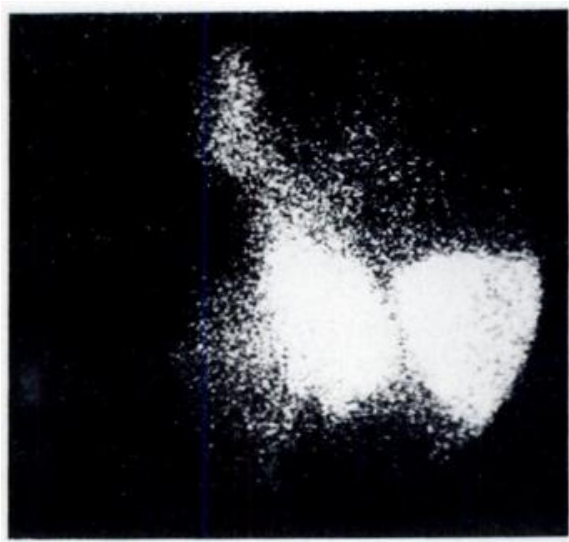

Fig. 13

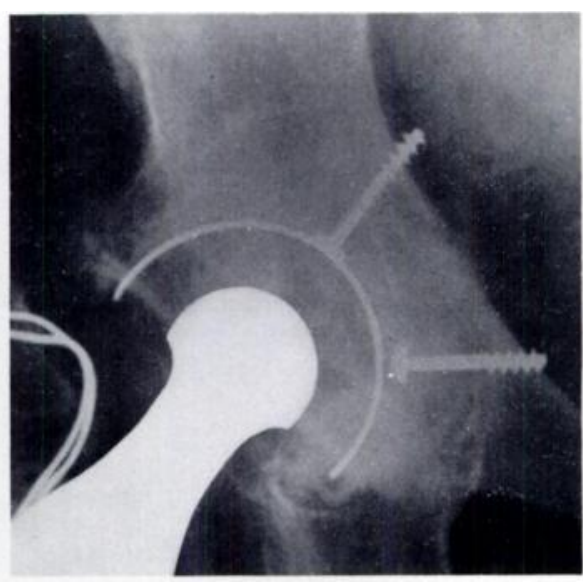

Fig. 12

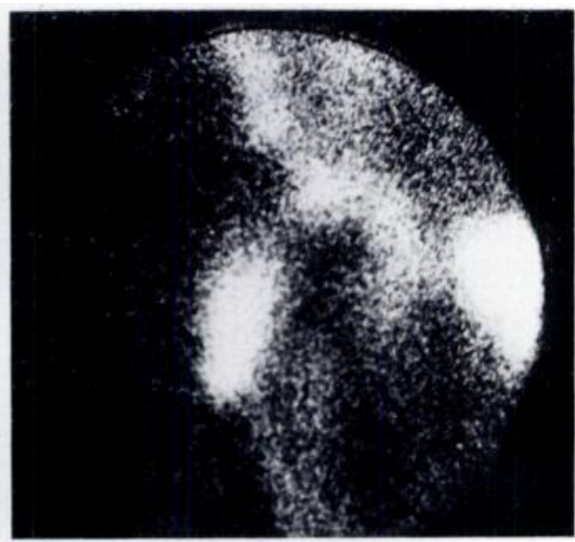

Fig. 14

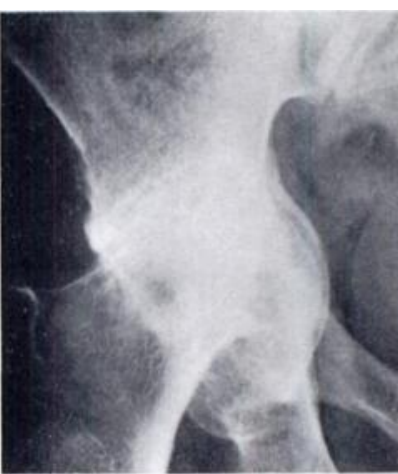

Fig. 15

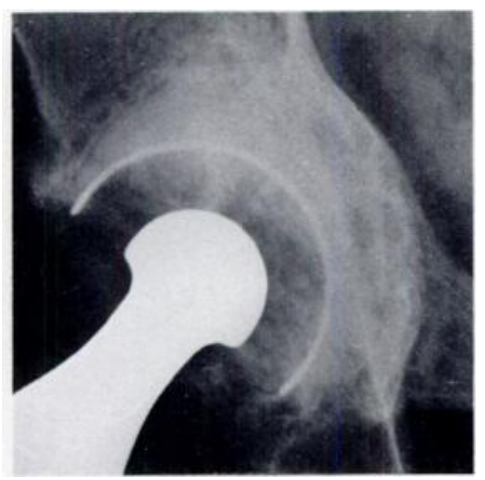

Fig. 16

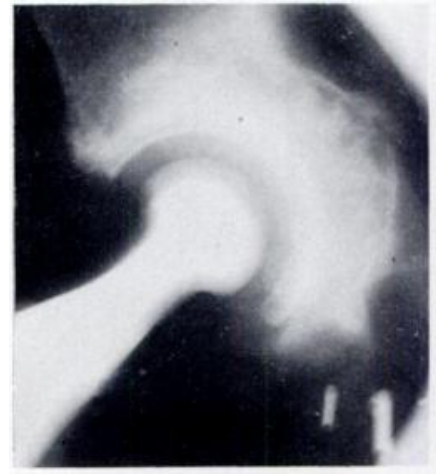

Fig. 17

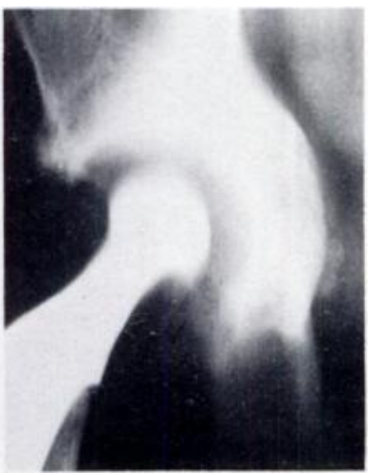

Fig. 18

Figure 15-Protrusio due to rheumatoid arthritis. Figure 16-Sixteen months after operation the graft shows radiological evidence of incorporation. Figure 17-The tomogram one month after operation. Figure 18-One year after operation tomography confirms union of the graft. Tomography of two other hips in the series showed similar results.

(1956), and based on the work of Siffert (1955), still hold true today. In an arthroplasty, strip grafts must be further condemned because of the likelihood of their being surrounded by cement and thus isolated from vascular ingrowth. Two of Charnley's prostheses which prolapsed centrally had had strip grafts in the acetabulum (Charnley 1979). Finally, the massive advantages of a bony acetabular floor in the event of a later revision need hardly be stressed.

Nothing is gained by adding wire mesh to the cement in the depths of the acetabulum. The cement and prosthesis form a solid block which acts as a single unit once the cement has set, regardless of the presence or absence of wire in its substance. The placement of wire mesh over the graft and in the acetabular bed before insertion of the cement can only interfere with cleaning of the trabecular keying surface and prevent an easy inflow of the cement in its plastic state. The need for attention to these factors has been stressed by Lee $e t a l$. (1978). 
The use of the excised femoral head to fill the acetabular defect has gained important impetus from Harris, Crothers and Oh (1977) who have used it with success to buttress the acetabular roof in dysplastic acetabula. While the principle has yet to stand the test of time, it seems logical to expect living bone to stand up better in the longer term than man-made reinforcements.

I am indebted to my colleagues Messrs Desmond Dall and Rael Jaffe, each of whom has allowed me to include a patient in the series.

\section{REFERENCES}

Arai M. The resultant force on the femoral head in rheumatoid arthritis. Arch Orthop Unfallchir 1975;81:163-8.

Charnley J. Low friction arthroplasty of the hip: theory and practice. Berlin, Heidelberg, New York: Springer-Verlag, 1979:45-52.

Fischer O. Der Gang des Menschen II. Teil: Die Bewegung des Gesamtschwerpunktes und die äuberen Krafte. Abhand Math Phys Cl König Wissenschafien. 1899;25:1-163.

Harris WH, Crothers O, Oh I. Total hip replacement and femoral-head bone-grafting for severe acetabular deficiency in adults. $J$ Bone Joint Surg $[$ Am $]$ 1977;59-A:752-9.

Jefferiss CD, Lee AJC, Ling RSM. Thermal aspects of self-curing polymethylmethacrylate. J Bone Joint Surg [Br] 1975;57-B:511-8

Lee AJC, Ling RSM, Vangala SS, Buck S. Some clinically relevant variables affecting the mechanical behaviour of bone cement. $J$ Bone Joint Surg $[\mathrm{Br}] 1978 ; 60-\mathrm{B}: 137$.

Nicoll EA. The treatment of gaps in long bones by cancellous insert grafts. J Bone Joint Surg [Br] 1956;38-B:70-82.

Parker SM, Hastings DE. Protrusio acetabúlae in rheumatoid arthritis. J Bone Joint Surg [Br] 1974;56-B:587.

Pauwels F. Gesammelte Abhandlungen Zur functionellen Anatomie des Bewegungsapparates. Berlin, Heidelberg, New York: Springer-Verlag, 1965.

Salvati EA, Bullough P, Wilson PD Jr. Intrapelvic protrusion of the acetabular component following total hip replacement. Clin Orthop 1975;111:212-27.

Siffert RS. Experimental bone transplants. J Bone Joint Surg [Am] 1955;37-A:742-58.

Welch RB, Charnley J. Low-friction arthroplasty of the hip in rheumatoid arthritis and ankylosing spondylitis. Clin Orthop 1970;72:22-32. 